Recepción: 20 / 04 / 2017

Aceptación: 20 / 05 / 2017

Ciencias técnicas y aplicadas

Publicación: 15 / 07 / 2017

Artículo Científico

\title{
Café a base de plátano: otra estrategia posible desde la perspectiva micro-local en la Ciudad de Babahoyo, Ecuador
}

Banana-based coffee: another possible strategy from a micro-local perspective in the City of Babahoyo, Ecuador

Café a base de plátano: outra estratégia possível desde a perspectiva micro-local na Ciudad de Babahoyo, Equador

Susana P. Morán-Rodríguez ${ }^{\text {I }}$ smoran@utb.edu.ec

Eduardo H. Jiménez-Rendón II ejimenez@utb.edu.ec

Washington E. Pazmiño-Gavilánez III wpazmino@utb.edu.ec

Franklin R. Morales-Reyna IV fmorales@utb.edu.ec

Correspondencia: smoran@utb.edu.ec

I. Docente, Universidad Técnica de Babahoyo, Babahoyo, Ecuador.

II. Docente, Universidad Técnica de Babahoyo, Babahoyo, Ecuador.

III. Docente, Universidad Técnica de Babahoyo, Babahoyo, Ecuador.

IV. Docente, Universidad Técnica de Babahoyo, Babahoyo, Ecuador. 


\section{Abstract}

This article describes how the traditional marketing relationships cause an extension in the production chains, in which the producer obtains poor benefits derived from his activity, since in the chain of intermediaries is where in the long run the greater profits of the business. The small producers of the city of Los Ríos-Babahoyo in Ecuador have advanced in independent initiatives, trying to break through a complex market (coffee and banana), however, as small entrepreneurs are in need of strategies Effective marketing strategies that increase its competitive capacity and profitability, a business plan that considers the effectiveness of banana peel-based coffee cultivation could provide new ways of making and thinking about production from a community perspective, than to its Improve the living conditions of all the inhabitants of the Los Ríos-Babahoyo Canton.

Key words: Market; innovation; competitiveness. 


\section{Resumo}

En este artículo se descreve como as relações tradicionais de comercialização ocasionan un alargamiento em cadenas produtivas, em que o produto obtém mais favores dos mais baixos dos produtos da empresa, já que na cadeia de intermediários é onde está a maior parte restante as maiores ganancias do Negócio. Os pequenos produtos da cidade de Los Ríos - Babahoyo em Equador, han avançado em iniciativas independentes, que tratam de abrir um passo no mercado de por si complexo (café e plástico), não obstante como pequenos empresários estão nas necessidades de construir estratégias De comercialização efetiva que eleva sua capacidade competitiva e da rentabilidade, um plano de negócios que pondere a eficácia do cultivo do café a base de cascara de plátanos que aportar novas maneras de fazer e pensar a produção desde a perspectiva de lo comunitário, que a su Vez melhorando as condições de vida de todos os habitantes do Cantão Los Ríos-Babahoyo.

Palavras-chave: Mercado; inovação; competitividad. 


\section{Introducción.}

Los bananos y plátanos representan el cultivo frutícola número uno en el mundo tanto en términos de producción como de comercio con 98 millones de toneladas al año.

El desarrollo del Ecuador ha ido acompañado del surgimiento, reorganización y estímulo de las iniciativas organizativas de grupos de productores en pequeñas empresas, cuyo rol estratégico consiste en complementar la producción nacional y regional desde una perspectiva micro-local.

Los pequeños productores que orientan su actividad al cultivo del plátano y el café, se ven afectados por toda una cadena de intermediarios, en las que al momento de llegar el producto ya se le ha asignado un precio de venta. Esto obedece a la regulación del mercado que como condicionante que es, en efecto limita el que el pequeño productor obtenga márgenes de rentabilidad adecuados que garanticen como mínimo, el cubrimiento de los costos de producción, lo que de manera lógica impide cubrir el costo fundamental de la canasta básica para el sustento familiar y así poder costear mejores niveles de vida y bienestar.

Este fenómeno se presenta en todo el territorio Ecuatoriano, lo que hace necesario generar estrategias que coadyuven a mejorar la condición de los productores pequeños, mediante la puesta en práctica de ideas frescas, que sepan aprovechar todos los recursos disponibles para el fortalecimiento del sector agrícola. La utilización inteligente de la cáscara del plátano: un desecho orgánico, arroja verdaderas luces en este sentido.

En este contexto, es que las nuevas estructuras de negocios estudiadas, pensadas y planteadas en este artículo, contribuirán a generar un modelo diferente, que estimule unas relaciones comerciales más justas en las que el pequeño productor pueda obtener resultados económicos óptimos, más equivalentes al esfuerzo y al trabajo incorporado en la tarea de producción que necesariamente, sí es 
replanteada en términos de competitividad podría efectivamente aportar en positivo a un modelo económico que en lo nacional comienza a incluir a la producción local aguas abajo, como contracara al fenómeno de la globalización del Ecuador.

\section{Materiales y métodos.}

La competitividad es un aspecto relevante de todas las pequeñas y medianas empresas en un mundo absorbido por el homogéneo proceso de la globalización. Resulta claro que las organizaciones y los grupos organizados están impelidos por la nueva realidad, a ser más eficientes y eficaces en el manejo de las potencialidades y ventajas que las definen, en aras de afrontar los retos que impone un entorno siempre cambiante y estimulado a ello por la competencia entre empresas de una misma rama.

Todo esto conlleva a que las empresas adopten posiciones precisas respecto al posicionamiento en el mercado, precios, producción, mantenimiento, formación y capacitación técnica, marketing y publicidad por mencionar algunos. En este sentido, la competitividad se entiende como "aquella medida en la que el desempeño de una unidad productiva, ya sea una empresa, industria o la misma economía nacional, permita hacer una comparación de su posición con respecto a la de la competencia, y que a su vez, posibilite la identificación de las fortalezas y debilidades” (Rodríguez, 2006).

De allí que, este artículo aborde entre otros aspectos de la competitividad, el de la política de precios, que deriva a su vez de una estrategia de producción optimizada, sobre la base de la incorporación de la concha del plátano en un novedoso proceso de producción de café.

El planteamiento fundamental está en discernir si efectivamente, una alternativa como la expuesta tiene asidero en los hábitos de consumo de la ciudad de Los Ríos-Babahoyo, al menos inicialmente. 
Transformar los hábitos del consumo del café tradicionalmente cultivado de manera intensiva y asumidos por la población no es una tarea sencilla, más bien requiere como en efecto, de toda una estrategia explicativa y de posicionamiento del nuevo producto sobre los criterios del precio en tanto apuesta más fuerte, para así poder optar por un lugar en la dieta diaria de consumo de la población ponderando los beneficios que tiene para la salud el no empeño de químicos en los procesos productivos y las consecuencias consabidas del consumo en exceso de cafeína.

Esta posibilidad depende de dos variables bien precisas: la voluntad de los productores de adentrarse en nuevas maneras de producir, así como un estudio científico que demuestre su factibilidad como alternativa de sobrevivencia económica al garantizar una disminución de los costes en fertilizantes, en materias primas, en cuadros técnicos altamente formados por mencionar algunos.

No obstante, una propuesta alternativa como esta, que intenta posicionar un café cultivado a partir de un desecho orgánico proveniente del plátano representa todo un desafío. En este sentido, se desarrolló un trabajo de campo de tipo descriptivo, ya que la identificación de los hábitos y conocimiento del consumidor resultan vitales para su efectiva implementación, además y en función de ello, en el plano metodológico se adelantaron estudios mediante la aplicación de un instrumento tipo encuesta desde el cual se pudieron trazar las fases de un plan de negocios tentativo para el cantón Los Ríos-Babahoyo y la empresa de producción de un nuevo café sobre la base de la concha de plátano, que lucha por abrirse paso entre toda una gama de haciendas y empresas dedicadas al mismo ramo productivo pero de manera tradicional.

Se aplicaron en este sentido, entrevistas a 431 personas. De todo ello se pudo constatar el interés que la mayoría de la ciudadanía tiene respecto al nuevo producto, aunque el desconocimiento se expresa a nivel mayoritario en un $88 \%$ de los entrevistados. Sin embargo, la posibilidad de la producción del nuevo café es bastante grande, puesto que hay expectativas interesantes en la población que así lo 
constatan cuando se propone el precio como alternativa, como verdadero fundamento y base de la elección.

En este orden de ideas, se hace necesario recordar que la ventaja competitiva por excelencia de una empresa respecto a otra similar, radica en su capacidad inicial de reducir sus costos de producción, lo que redundaría en una disminución del precio de venta. Si ello viene acompañado de una asertiva modalidad de posicionamiento el reto quedaría parcialmente ganado en un principio.

\section{Resultados.}

Las Encuestas realizadas en la Ciudad de Babahoyo, nos reflejan que la Ciudadanía Babahoyense en un gran porcentaje no ha consumido el café elaborado a base de cascara de verde, es decir, un $88 \%$, empero estarían dispuestos a consumirlo ya que es un producto $100 \%$ natural sin persevantes químicos que ayudara a la salud de los consumidores.

Además consideran que es una excelente idea, que una empresa se dedique a la producción y comercialización del mismo.

Por otro lado como empresa en formación, se tiene pleno conocimiento de que es un producto poco común y que se tendrá que implementar estrategias para posicionarlo en el mercado y en la mente de los consumidores.

Además, se observó de acuerdo a la recolección de datos y resultados a través de las encuestas efectuadas que la ciudadanía no conoce de este producto, lo que obliga a pensar en profundidad respecto a las maneras de alcanzar los objetivos planteados. 


\section{Discusión.}

En términos generales la población ha desperdiciado desde hace milenios la mayoría de las cosas que come y consume. La actualidad, mediante la ciencia y diversos estudios ha demostrado que podemos extraer muchos minerales y proteínas entre los desechos orgánicos que quedan como remanentes después del proceso alimenticio.

Ahora bien, ¿Debe continuar la sociedad ignorando la enorme pérdida alimentaria que significa no saber utilizar o consumir los alimentos que nos brinda la naturaleza y el trabajo? ¿Existen alternativas que reviertan la condición de ignorancia comúnmente practicada por la mayoría de la sociedad? ¿es posible otra alternativa de consumo más sana y accesible?

Las respuestas a estas interrogantes en el futuro parten de la disposición de la ciudadanía ante la exploración de otras alternativas. Suramérica se ha destacado desde los tiempos de las colonias por su enorme potencial en la producción de café, no obstante, en pocas oportunidades se ha podido diseñar una alternativa alimentaria ante lo tradicional, ante las costumbres seculares de la población, ante los hábitos de consumo.

La producción de un nuevo café es una alternativa en este sentido, los actores de la ciudad en pequeño número, quizás aún hoy en un estado embrionario, decidieron incursionar en la dura realidad empresarial del café y su complejo mercado a plantar cara ante lo que ya es una práctica común en el ecuatoriano: tomarse un cafecito.

\section{Recomendaciones.}

Dos recomendaciones resultan básicas para el desarrollo y posicionamiento del nuevo café, a saber que: es imprescindible saber aplicar políticas innovadoras de marketing en aras de que la ciudadanía 
tenga conocimiento del producto e impulsar una difusión constante del producto que se oferta para que la colectividad concientice y consuma este tipo de café por el cuidado de su salud.

\section{Conclusiones.}

En este marco, podemos encontrar claros beneficios desde los cuales trazar una estrategia que convenza a la gente sobre el uso de la cáscara del plátano, dado que posee antioxidantes naturales cuyos efectos positivos resultan idénticos a los del café pero a diferencia de éste no produce adicciones. Por consiguiente, siendo esta una de las principales razones por la que se impulsa un nuevo tipo de café, un sustituto al café tradicional que contribuya a erradicar la adicción que produce un consumo excesivo de este producto cobra plena vigencia en una sociedad castigada por el consumo irracional y cada vez más costoso de toda una gama de productos básicos para la vida plena.

Solo el tiempo y la enorme voluntad de contribuir con un futuro diferente darán cuenta del éxito de una aspiración noble como esta, porque a fin de cuentas que son los seres humanos sino el producto de una realidad históricamente determinada, que puede ser hasta cierto punto influenciada por las ideas y las aspiraciones de los actores sociales que la habitan, la padecen o la disfrutan, según el caso.

\section{Bibliografía.}

Hit A. Michael, R.Duane arelad, Hoskkison E. Robert Administración Estratégica: competitividad y globalización, México DF. Cenage learnig 2008

García Echeverria Santiago, introducción a la economía de la empresa, Madrid, ediciones Días de santos, 1994

Gilbert Daniel. F, Freeman Edward, Stoner F.A james, Administración, México, Pearson educación, 1996 
Mondy.R. Wayne y Noe Roberto, M, Administración de recursos humanos, Pearson educación, México 2005 